\title{
Reliability, factor structure and validity of the Dutch Eysenck Personality Profiler
}

Citation for published version (APA):

Muris, P. E. H. M., Schmidt, H. G., Merckelbach, H. L. G. J., \& Rassin, E. G. C. (2000). Reliability, factor structure and validity of the Dutch Eysenck Personality Profiler. Personality and Individual Differences, 29, 857-868. https://doi.org/10.1016/S0191-8869(99)00237-8

Document status and date:

Published: 01/01/2000

DOI:

10.1016/S0191-8869(99)00237-8

Document Version:

Publisher's PDF, also known as Version of record

\section{Please check the document version of this publication:}

- A submitted manuscript is the version of the article upon submission and before peer-review. There can be important differences between the submitted version and the official published version of record. People interested in the research are advised to contact the author for the final version of the publication, or visit the DOI to the publisher's website.

- The final author version and the galley proof are versions of the publication after peer review.

- The final published version features the final layout of the paper including the volume, issue and page numbers.

Link to publication

\footnotetext{
General rights rights.

- You may freely distribute the URL identifying the publication in the public portal. please follow below link for the End User Agreement:

www.umlib.nl/taverne-license

Take down policy

If you believe that this document breaches copyright please contact us at:

repository@maastrichtuniversity.nl

providing details and we will investigate your claim.
}

Copyright and moral rights for the publications made accessible in the public portal are retained by the authors and/or other copyright owners and it is a condition of accessing publications that users recognise and abide by the legal requirements associated with these

- Users may download and print one copy of any publication from the public portal for the purpose of private study or research.

- You may not further distribute the material or use it for any profit-making activity or commercial gain

If the publication is distributed under the terms of Article $25 \mathrm{fa}$ of the Dutch Copyright Act, indicated by the "Taverne" license above, 


\title{
Reliability, factor structure and validity of the Dutch Eysenck Personality Profiler
}

\author{
Peter Muris $^{\mathrm{a}, *}$, Henk Schmidt ${ }^{\mathrm{b}}$, Harald Merckelbach ${ }^{\mathrm{b}}$, Eric Rassin ${ }^{\mathrm{b}}$

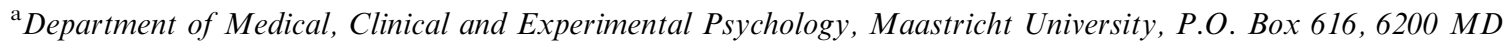 \\ Maastricht, The Netherlands \\ ${ }^{\mathrm{b}}$ Department of Psychology, Maastricht University, Maastricht, The Netherlands
}

Received 14 July 1999; received in revised form 11 October 1999; accepted 22 October 1999

\begin{abstract}
The Eysenck Personality Profiler (EPP) is a questionnaire measuring 21 primary personality traits that are thought to constitute the three supertraits of Extraversion, Neuroticism and Psychoticism. The present study examined the reliability, factor structure and convergent validity of the Dutch translation of the EPP in a sample of introductory psychology students $(N=215)$. Results indicate that the internal consistency of most EPP scales was satisfactory. Furthermore, exploratory and confirmatory factor analyses showed that the to-be-expected three-factor structure provided a reasonable fit for EPP data. Finally, Extraversion, Neuroticism and Psychoticism were found to correlate in a meaningful way with the "big 5" supertraits as indexed by the Five-Factor Personality Inventory. (C) 2000 Elsevier Science Ltd. All rights reserved.
\end{abstract}

\section{Introduction}

It is widely accepted that personality traits are hierarchically arranged with specific traits at lower levels in the hierarchy and global traits at the top (Goldberg, 1993). The trait model formulated by H.J. Eysenck (e.g. Eysenck \& Eysenck, 1985) is a good example of such a hierarchical approach to personality. Briefly, Eysenck specified a number of lower-order traits that are thought to define three supertraits: Extraversion, Neuroticism and Psychoticism. The

\footnotetext{
* Corresponding author. Tel.: +31-43-388-1264; fax: +31-43-367-0968.

E-mail address: p.muris@dep.unimaas.nl (P. Muris).
} 
Table 1

The Eysenck Personality Profiler: three supertraits (Extraversion, Neuroticism and Psychoticism), 21 primary traits, a description and an example of an item of each trait

\begin{tabular}{|c|c|c|c|}
\hline Supertrait & Primary trait & Description, high scorers... & Item \\
\hline \multirow[t]{7}{*}{ Extraversion } & Active & $\begin{array}{l}\text { are active and energetic, enjoy all } \\
\text { kinds of physical activity and move } \\
\text { rapidly from one activity to } \\
\text { another }\end{array}$ & $\begin{array}{l}\text { "Do you normally tend to do } \\
\text { things at a rapid rate?" }\end{array}$ \\
\hline & Sociability & $\begin{array}{l}\text { seek out the company of other } \\
\text { people easily and are generally } \\
\text { happy and comfortable in sociable } \\
\text { situations }\end{array}$ & $\begin{array}{l}\text { "Do you like mixing with lots of } \\
\text { other people?" }\end{array}$ \\
\hline & Expressiveness & $\begin{array}{l}\text { tend to be sentimental, } \\
\text { sympathetic, volatile and } \\
\text { demonstrative }\end{array}$ & $\begin{array}{l}\text { "Do you tell your friends what you } \\
\text { think is wrong with them?" }\end{array}$ \\
\hline & Assertiveness & $\begin{array}{l}\text { are independent, dominant and } \\
\text { stand up for their rights }\end{array}$ & $\begin{array}{l}\text { "Do you always argue if you think } \\
\text { you are right?" }\end{array}$ \\
\hline & Ambition & $\begin{array}{l}\text { are ambitious, hard-working, } \\
\text { competitive and place a high value } \\
\text { on productivity within their area of } \\
\text { work }\end{array}$ & $\begin{array}{l}\text { "Do you work hard for success } \\
\text { rather than day-dream about it?" }\end{array}$ \\
\hline & Dogmatic & $\begin{array}{l}\text { have set uncompromising views on } \\
\text { most matters and tend to defend } \\
\text { them vigorously and vociferously }\end{array}$ & $\begin{array}{l}\text { "Do you have clear ideas about } \\
\text { what is right and wrong?" }\end{array}$ \\
\hline & Aggressive & $\begin{array}{l}\text { are given to direct or indirect } \\
\text { expression of Aggression }\end{array}$ & $\begin{array}{l}\text { "Do you often make biting } \\
\text { remarks about other people?" }\end{array}$ \\
\hline \multirow[t]{4}{*}{ Neuroticism } & Inferiority & $\begin{array}{l}\text { have a low opinion of themselves, } \\
\text { believe that they are failures }\end{array}$ & $\begin{array}{l}\text { "Do you often have doubts about } \\
\text { your abilities?" }\end{array}$ \\
\hline & Unhappiness & $\begin{array}{l}\text { are pessimistic, gloomy, depressed } \\
\text { and disappointed with their } \\
\text { existence }\end{array}$ & $\begin{array}{l}\text { "Do you often feel lonely even } \\
\text { when you are with other people?" }\end{array}$ \\
\hline & Anxiety & $\begin{array}{l}\text { are easily upset by things that go } \\
\text { wrong and inclined to worry }\end{array}$ & "Are you a nervous person?" \\
\hline & Dependence & $\begin{array}{l}\text { lack self-reliance, think of } \\
\text { themselves as helpless people, are } \\
\text { pushed around by other people and } \\
\text { tend to obey institutional power }\end{array}$ & $\begin{array}{l}\text { "Are you easily persuaded by the } \\
\text { arguments of other people?" }\end{array}$ \\
\hline
\end{tabular}


Hypochondria

Guilt

Obsessiveness

Psychoticism

Impulsiveness

Irresponsible

Manipulativeness

Sensation-seeking

Tough-mindedness

Practical acquire psychosomatic symptoms and imagine that they are ill; they show a great deal of concern about

their physical health

are self-blaming, self-abasing and

troubled by their conscience

are careful, conscientious, highly

disciplined and easily irritated by

things that are unclean, untidy or

out of place

like to live dangerously and seek

rewards with little concern for

consequences

are inclined to act on the spur of

the moment and make hurried

decisions

are inclined to be casual, careless,

late with commitments and

unpredictable

are detached, calculating, shrewd,

expedient and self-interested in

their dealings with other people

are seeking thrills in life, have an

insatiable thirst for novel

experiences

are unconcerned about crawling

insect, the sight of blood and othe

gruesome spectacles; They probably

enjoy violence, obscenity and

swearing

are inclined to be practical, are

interested in doing things rather

than thinking about them
"Are you often bothered by palpitations of the heart?"

"Do you believe that you have committed unpardonable sins?"

"Do you feel very uncomfortable if your workspace gets untidy?' action rather than profound thought or study?'” 
Extraversion dimension pertains to characteristics such as sociability, craving for excitement, liveliness, activeness and dominance. The Neuroticism dimension has to do with the ease and frequency with which an individual becomes upset and distressed, with greater moodiness, anxiety and depression reflecting higher levels of Neuroticism. The Psychoticism dimension refers to a predisposition to display sociopathic behavior. According to Eysenck (1992a), people high on Psychoticism tend to be hostile, manipulative, impulsive and adventurous.

More recently, Eysenck (see Eysenck, Wilson \& Jackson, 1996a) developed the Eysenck Personality Profiler (EPP), an instrument measuring 21 lower-order traits hypothesized to be definers of the three supertraits Extraversion, Neuroticism and Psychoticism. Table 1 shows the 21 EPP scales, a brief description and a typical example of an item of each trait.

So far, few studies have examined the psychometric properties of the EPP. As a first test of the instrument, Eysenck, Barrett, Wilson and Jackson (1992) carried out reliability and factor analyses on the 21 EPP traits in a large sample of 1019 men and 580 women. Results showed that most EPP scales were reliable in terms of internal consistency: Cronbach's alphas varied between 0.41 and 0.89 with a mean of 0.72 . Initial exploratory factor analysis provided mixed support for the original model as presented in Table 1. While the Neuroticism factor was defined by all seven intended traits and the Psychoticism factor was composed of six out of the seven a priori Psychoticism scales along with the lower-order Extraversion traits of Expressive and Aggressive, the third factor bore little resemblance to Extraversion; only Ambition and Assertive showed the expected loading on this factor. In an attempt to further elucidate the complex structure of the 21 traits, Eysenck et al. (1992) performed a targeted factor rotation. This analysis revealed a pattern of results that was more in keeping with the model; 18 out of 21 lower-order scales could be forced onto their intended factor, although a number of Extraversion and Psychoticism traits had substantial secondary loadings.

Costa and McCrae (1995) had 229 adults complete the EPP and a concurrent personality questionnaire, namely the Revised NEO Personality Inventory (NEO-PI-R; Costa \& McCrae, 1992a). This instrument is based on the notion that the basic structure of personality involves five superfactors, termed the "big 5" (i.e. Neuroticism, Extraversion, Conscientiousness, Agreeableness and Openness) rather than Eysenck's three factors. Thus, the NEO-PI-R measures 30 lower-order traits each representing one of the five supertraits. The main results of Costa and McCrae's (1995) study can be summarized as follows. First, reliability coefficients of the EPP scales were generally satisfactory and highly similar to those reported by Eysenck et al. (1992): alphas ranged from 0.50 to 0.87 with a mean of 0.73 . Second, exploratory and targeted factor analyses revealed a rather good fit for the hypothesized three-factor structure of the EPP. That is, Neuroticism and Extraversion were defined by all hypothesized traits, whereas Psychoticism was defined by six of the seven intended scales. However, as was the case in the Eysenck et al. (1992) study, a number of Extraversion and Psychoticism scales had secondary loadings on other factors. For example, the lower-order Extraversion scales Aggressive and Expressive also loaded substantially on Psychoticism, whereas the lower-order Psychoticism trait of Sensation Seeking also loaded on Extraversion. Third and finally, EPP scales correlated in a theoretically meaningful way with NEO-PI-R scales. That is, lower-order EPP traits showed remarkable convergence with similarly named NEO-PI-R scales. Furthermore, at the higher-order level, EPP Neuroticism and Extraversion were found to be significantly linked to their NEO-PI-R counterparts, whereas EPP Psychoticism correlated 
negatively with both NEO-PI-R Agreeableness and Conscientiousness (see for similar results, Goldberg (1993) and Zuckerman, Kuhlman, Joireman, Teta and Kraft (1993)). Although it is clear from their discussion that Costa and McCrae (1995) advocate a five-factor structure of personality, their findings support the reliability and validity of the EPP.

The present study was a first attempt to evaluate the psychometric properties of the Dutch translation of the EPP. A sample of 215 students completed the profiler during an introductory psychology course. The following issues were addressed. First, the reliability (i.e. internal consistency) of the EPP scales was investigated. Second, the factor structure of the EPP was examined in detail. Not only exploratory factor analysis was performed, but also confirmatory factor analysis. With this technique it becomes possible to study to what extent the data are in line with the hypothesized model. Third, to further examine the convergent validity of the EPP, a subsample of the students also completed the Five-Factor Personality Inventory (FFPI; Hendriks, Hofstee, De Raad \& Angleitner, 1995; Hendriks, 1997), which is a Dutch equivalent of the NEO-PI-R. It was predicted that the EPP Extraversion and Neuroticism supertraits would be significantly connected to their FFPI counterparts. Furthermore, Psychoticism was expected to be negatively linked with the "big 5" traits of Agreeableness and Conscientiousness (cf. supra).

As an aside, it should be noted that Eysenck, Wilson and Jackson (1996b) also constructed a shortened version of the EPP which consists of three scales for each supertrait. Thus, it seemed worthwhile to examine the reliability, factor structure and validity of the Short EPP as well.

\section{Method}

The sample consisted of 215 introductory psychology students (49 men and 166 women) with a mean age of 19.5 years (S.D. $=2.1$, range $18-38$ years). They volunteered to complete the Dutch translation of the Eysenck Personality Profiler (EPP). A subsample of these students $(N=163,20$ men and 143 women, mean age: 19.5 years, S.D. $=2.3$, range $18-38$ years $)$ also filled in the Five-Factor Personality Inventory (FFPI).

The EPP consists of 440 items that can be allocated to 21 primary trait scales (see Table 1) and a Lie scale. Items are answered "yes", "no", or "can't decide". Each scale is scored by counting two points for every "yes" or "no" option endorsed in the same direction given for the scale and 1 point for every "can't decide" option that is endorsed. a total score for each scale is obtained by summing these points (range 0-40). Total scores for the supertraits Extraversion, Neuroticism and Psychoticism can be calculated by summing across the seven appropriate trait scores (range 0-280). The shortened version of the EPP (180 items) contains nine primary trait scales. In this version, Activity, Sociability and Assertiveness represent Extraversion, Inferiority, Unhappiness and Anxiety constitute Neuroticism, while Risk-taking, Impulsiveness and Irresponsibility reflect Psychoticism. The EPP was translated into Dutch by the first and second author. A professional translator checked and corrected the translation.

The FFPI assesses the "big 5" factors of personality: Extraversion, Agreeableness, Conscientiousness, Emotional Stability and Autonomy (Openness). The questionnaire consists of 100 brief statements (e.g. Extraversion: "loves to chat", Agreeableness: "accepts people as they are", Conscientiousness: "does things according to a plan", Emotional Stability: "gets 
overwhelmed by emotions" (negatively formulated item) and Autonomy: "wants to form his/ her own opinion"). Items are rated on 5-point scales with $1=$ "not at all applicable" and $5=$ "very much applicable". After recoding negatively formulated items, a total score can be calculated for each factor (range 20-100). In the present study, Cronbach's alphas for the FFPI factors were 0.83 for Extraversion, 0.54 for Agreeableness, 0.74 for Conscientiousness, 0.69 for Emotional Stability and 0.63 for Autonomy.

\subsection{Statistical analysis}

The statistical package for social sciences (SPSS) was used to compute descriptive statistics and to carry out the exploratory factor analyses. For confirmatory factor analysis, the structural equations modeling technique (EQS; Bentler, 1989) was used. EQS provides a powerful system to test the hypothesized factor structure of a questionnaire. A Pearson correlation matrix based on EPP scale scores was used as the input data for the confirmatory factor analyses (estimation method: maximum likelihood). EQS produces a wide range of goodness-of-fit indices of which the following were used in the present study: (a) $\chi^{2}$ divided by degrees of freedom (with large sample sizes as in the current study, this value should be around 4.00 or lower; the lower this value, the better the fit), (b) the average absolute standardized residuals (AASR; this value should be 0.05 or lower; the lower this value, the better the fit), (c) the root mean square error of approximation (RMSEA; values up to 0.08 represent reasonable errors of approximation (Browne \& Cudeck, 1993; the lower this value, the better the fit), (d) the root mean squared residual (RMR; this value should be close to 0.05 or lower; the lower this value, the better the fit), (e) the comparative fit index (CFI; this value should be 0.90 or higher for a good fit; the higher this value, the better the fit) and (f) the goodness-of-fit index (GFI; this value should be 0.90 or higher for a good fit; the higher the value, the better the fit). The present sample size was too small (with only $49 \mathrm{men}$ ) to carry out factor analyses for men and women separately. Therefore, only the results for the total sample will be presented hereafter.

\section{Results}

\subsection{Internal consistency of EPP scales}

Table 2 shows mean EPP scores (standard deviations) for the total sample and for men and women separately. As can be seen, there were gender differences for a number of EPP scales: Men displayed higher scores on a number of Extraversion and Psychoticism scales than women, whereas women generally had somewhat higher Neuroticism scores than men, although only significantly so for Hypochondria.

For most EPP scales, internal consistency as measured by Cronbach's alpha was adequate (see Table 2). Only the alphas for Expressiveness $(\alpha=0.46)$, Dogmatic $(\alpha=0.48)$ and Aggressive $(\alpha=0.54)$ were below acceptable limits. 


\subsection{Factor structure of the EPP}

Exploratory factor analysis (principal components, oblimin rotated) was performed on the 21 EPP scales in order to examine the hypothesized three-factor structure. Table 3 displays the 21 EPP traits and their loadings on the three factors after rotation. As can be seen, most traits loaded $>0.30$ on their supposed factor (Neuroticism, Psychoticism and Extraversion). Together, the three factors accounted for $50.4 \%$ of the variance. Only Obsessiveness and

Table 2

Means (standard deviations), gender differences and reliability coefficients (Cronbach's alphas) for the various scales of the Eysenck Personality Profiler

\begin{tabular}{|c|c|c|c|c|}
\hline & Total group $(N=215)$ & Males $(n=49)$ & Females $(n=166)$ & $\alpha$ \\
\hline \multicolumn{5}{|l|}{ Extraversion } \\
\hline Total & $133.1(25.4)$ & $146.9(25.0)$ & $129.1(24.1)^{\mathrm{a}}$ & 0.85 \\
\hline Total (Short) ${ }^{\mathrm{b}}$ & $66.6(16.5)$ & $75.3(14.8)$ & $64.0(16.1)^{\mathrm{a}}$ & 0.85 \\
\hline Active & $20.7(7.2)$ & $23.0(7.0)$ & $20.0(7.2)$ & 0.74 \\
\hline Sociability & $26.1(7.1)$ & $28.3(6.7)$ & $25.4(7.0)$ & 0.75 \\
\hline Expressiveness & $20.4(5.1)$ & $21.4(5.3)$ & $20.1(5.1)$ & 0.46 \\
\hline Assertiveness & $19.8(7.2)$ & $23.9(5.7)$ & $18.6(7.2)^{\mathrm{a}}$ & 0.76 \\
\hline Ambition & $17.6(6.8)$ & $17.6(7.0)$ & $17.7(6.7)$ & 0.72 \\
\hline Dogmatic & $14.0(4.3)$ & $15.4(4.5)$ & $13.6(4.2)$ & 0.48 \\
\hline Aggressive & $14.5(5.2)$ & $17.2(6.1)$ & $13.7(4.6)^{\mathrm{a}}$ & 0.54 \\
\hline \multicolumn{5}{|l|}{ Neuroticism } \\
\hline Total & $67.6(35.0)$ & $63.2(35.1)$ & $68.9(35.0)$ & 0.94 \\
\hline Total (Short) ${ }^{\mathrm{c}}$ & $35.3(21.8)$ & $31.5(22.0)$ & $36.4(21.7)$ & 0.93 \\
\hline Inferiority & $12.6(9.0)$ & $9.7(8.1)$ & $13.5(9.1)$ & 0.87 \\
\hline Unhappiness & $9.1(8.3)$ & $10.2(9.2)$ & $8.8(8.0)$ & 0.88 \\
\hline Anxiety & $13.6(7.6)$ & $11.7(7.3)$ & $14.1(7.6)$ & 0.80 \\
\hline Dependence & $8.4(5.6)$ & $9.0(6.9)$ & $8.3(5.1)$ & 0.71 \\
\hline Hypochondria & $6.1(5.5)$ & $3.9(3.2)$ & $6.7(5.9)^{\mathrm{a}}$ & 0.74 \\
\hline Guilt & $7.4(5.9)$ & $8.2(6.0)$ & $7.2(5.9)$ & 0.76 \\
\hline Obsessiveness & $10.3(5.7)$ & $10.5(5.9)$ & $10.3(5.6)$ & 0.66 \\
\hline \multicolumn{5}{|l|}{ Psychoticism } \\
\hline Total & $125.0(25.6)$ & $142.9(24.2)$ & $119.8(23.6)^{\mathrm{a}}$ & 0.85 \\
\hline Total (Short) ${ }^{\mathrm{d}}$ & $57.4(16.7)$ & $65.3(16.1)$ & $55.0(16.2)^{\mathrm{a}}$ & 0.85 \\
\hline Risk-taking & $19.4(6.6)$ & $22.3(6.5)$ & $18.6(6.4)^{\mathrm{a}}$ & 0.69 \\
\hline Impulsiveness & $17.8(7.5)$ & $20.1(7.8)$ & $17.2(7.3)$ & 0.76 \\
\hline Irresponsibility & $20.1(6.4)$ & $22.9(5.6)$ & $19.3(6.4)^{\mathrm{a}}$ & 0.68 \\
\hline Manipulativeness & $12.1(5.3)$ & $14.2(4.9)$ & $11.5(5.3)^{\mathrm{a}}$ & 0.60 \\
\hline Sensation-seeking & $20.5(7.3)$ & $25.1(6.8)$ & $19.1(6.9)^{\mathrm{a}}$ & 0.74 \\
\hline Tough-minded & $17.2(6.0)$ & $23.0(5.9)$ & $15.5(4.8)^{\mathrm{a}}$ & 0.60 \\
\hline Practical & $18.2(7.1)$ & $15.8(7.9)$ & $18.8(6.8)$ & 0.74 \\
\hline Lie & $12.4(6.1)$ & $9.7(6.1)$ & $13.2(6.0)^{\mathrm{a}}$ & 0.70 \\
\hline
\end{tabular}

${ }^{\text {a }}$ Significant gender difference at $P<0.05 / 28$.

${ }^{\mathrm{b}}$ The Short Extraversion scale consists of Active, Sociability and Assertiveness.

${ }^{\mathrm{c}}$ The Short Neuroticism scale consists of Inferiority, Unhappiness and Anxiety.

${ }^{\mathrm{d}}$ The Short Psychoticism scale consists of Risk-taking, Impulsiveness and Irresponsibility. 
Practical did not load on their intended factor. Furthermore, it should be noted that some Extraversion traits (i.e. Sociability, Assertiveness and Aggressive) had a substantial secondary loading on Psychoticism; Aggressive loaded even stronger on Psychoticism than on Extraversion.

Confirmatory factor analysis indicated that the three-factor model provided a moderate fit for the data: $\chi^{2} / \mathrm{df}=2.3, \mathrm{AASR}=0.05, \mathrm{RMSEA}=0.07, \mathrm{RMR}=0.06, \mathrm{CFI}=0.85$, and $\mathrm{GFI}=0.84$.

\subsection{Factor structure of the Short EPP}

The results of the exploratory factor analysis performed on the nine scales of the shortened version of the EPP are shown in Table 4. As can be seen, all scales loaded on the three to-beexpected factors. The factors together accounted for $70.6 \%$ of the variance. Again, the Extraversion scales Sociability and Assertiveness appeared to have substantial loadings on Psychoticism.

Confirmatory factor analysis confirmed that the three-factor model of the Short EPP

Table 3

Factor structure obtained by means of exploratory factor analysis (principal components, oblimin rotated) of the 21 Eysenck Personality Profiler scales ${ }^{\mathrm{a}}$

\begin{tabular}{|c|c|c|c|}
\hline & Neuroticism & Psychoticism & Extraversion \\
\hline Inferiority & 0.82 & & \\
\hline Unhappiness & 0.85 & & \\
\hline Anxiety & 0.80 & & \\
\hline Dependence & 0.79 & & \\
\hline Hypochondria & 0.62 & & \\
\hline Guilt & 0.71 & 0.31 & \\
\hline Obsessiveness & & & 0.54 \\
\hline Risk-taking & & 0.79 & \\
\hline Impulsiveness & & 0.72 & \\
\hline Irresponsibility & & 0.67 & -0.32 \\
\hline Manipulativeness & & 0.30 & \\
\hline Sensation-seeking & & 0.76 & \\
\hline Tough-minded & -0.37 & 0.43 & \\
\hline Practical & & & -0.45 \\
\hline Active & -0.32 & & 0.58 \\
\hline Sociability & -0.43 & 0.30 & 0.40 \\
\hline Expressiveness & & & 0.43 \\
\hline Assertiveness & -0.42 & 0.49 & 0.50 \\
\hline Ambition & & & 0.75 \\
\hline Dogmatic & & & 0.50 \\
\hline Aggressive & & 0.58 & 0.35 \\
\hline Eigenvalue & 4.5 & 4.0 & 2.1 \\
\hline$\%$ Variance & 21.5 & 18.9 & 10.0 \\
\hline
\end{tabular}

\footnotetext{
${ }^{\text {a }}$ Only factor loadings $>0.30$ are shown. Factor loadings of EPP scales that load on the hypothesized superfactor are printed in bold.
} 
Table 4

Factor structure obtained by means of exploratory factor analysis (principal components, oblimin rotated) of the nine Short version Eysenck Personality Profiler scales ${ }^{\mathrm{a}}$

\begin{tabular}{lccr}
\hline & Neuroticism & Psychoticism & Extraversion \\
\hline Inferiority & $\mathbf{0 . 8 9}$ & & \\
Unhappiness & $\mathbf{0 . 8 3}$ & & $\mathbf{0 . 8 2}$ \\
Anxiety & $\mathbf{0 . 8 7}$ & $\mathbf{0 . 7 5}$ & $\mathbf{0 . 8 4}$ \\
Risk-taking & & & $\mathbf{0 . 8 7}$ \\
Impulsiveness & & 0.30 & $\mathbf{0 . 6 1}$ \\
Irresponsibility & -0.48 & 0.32 & $\mathbf{0 . 6 5}$ \\
Active & -0.45 & 2.2 & 1.1 \\
Sociability & 3.1 & 24.6 & 12.1 \\
Assertiveness & 33.9 & & \\
Eigenvalue & & & \\
\% Variance & & & \\
\hline
\end{tabular}

${ }^{a}$ Only factor loadings $>0.30$ are shown. Factor loadings of EPP scales that load on the hypothesized superfactor are printed in bold.

provided a rather satisfactory fit for the data: $\chi^{2} / \mathrm{df}=4.1, \mathrm{AASR}=0.04, \mathrm{RMSEA}=0.09, \mathrm{RMR}=$ $0.06, \mathrm{CFI}=0.90$, and $\mathrm{GFI}=0.91$.

\subsection{Relationships between EPP and FFPI}

Mean scores on the 5 FFPI scales were 59.7 (S.D. = 4.8) for Extraversion, 63.5 (S.D. $=5.4$ ) for Agreeableness, 64.1 (S.D. = 5.2) for Conscientiousness, 59.3 (S.D. = 5.0) for Emotional Stability and 60.4 (S.D. $=5.6)$ for Autonomy.

Table 5 shows correlations (corrected for gender) between the EPP supertraits Extraversion, Neuroticism and Psychoticism and the "big 5" as measured by the FFPI. As can be seen, the to-be-expected pattern of findings emerged. That is, EPP Extraversion and Neuroticism

Table 5

Correlations (corrected for gender) between the Eysenck Personality Profiler supertraits and the "big 5" as measured by the FFPI $^{\mathrm{a}}$

\begin{tabular}{lccc}
\hline & \multicolumn{2}{c}{ EPP } & \\
\cline { 2 - 4 } FFPI & Extraversion & Neuroticism & Psychoticism \\
\hline Extraversion & $\mathbf{0 . 5 6}^{*}$ & $-0.27^{*}$ & 0.15 \\
Agreeableness & $-0.27^{*}$ & 0.06 & $-\mathbf{0 . 2 3}^{*}$ \\
Conscientiousness & 0.09 & -0.12 & $-\mathbf{0 . 5 3}^{*}$ \\
Emotional Stability & 0.15 & $-\mathbf{0 . 7 3}$ & -0.08 \\
Autonomy & 0.16 & 0.05 & $0.24^{*}$ \\
\hline
\end{tabular}

\footnotetext{
${ }^{\text {a }} N=163$. FFPI $=$ Five Factor Personality Inventory. ${ }^{*} P<0.05 / 15$. Correlations between scales that were pre-
} dicted to be linked are printed in bold. 
correlated in the expected direction with their FFPI counterparts Extraversion and Emotional Stability ( $r$ s were $0.56, P<0.001$ and $-0.73, P<0.001$, respectively). Furthermore, EPP Psychoticism was negatively associated with Agreeableness $(r=-0.23, P<0.005)$ and Conscientiousness $(r=-0.52, P<0.001)$, indicating that individuals who score high on Psychoticism tend to be less agreeable and conscientious.

For the Short EPP, highly similar results were obtained. Correlations were $0.63(P<0.001)$ between the Short EPP Extraversion scale and its FFPI counterpart, $-0.76(P<0.001)$ between Neuroticism and FFPI Emotional Stability and $-0.66(P<0.001)$ between Psychoticism and FFPI Conscientiousness. The correlation between Psychoticism and Agreeableness no longer attained significance: $r=-0.09$.

\section{Discussion}

The EPP was developed to measure 21 specific personality traits that are thought to be definers of the three "Eysenckian" supertraits, Extraversion, Neuroticism and Psychoticism. The current study evaluated the psychometric properties of the Dutch translation of the EPP. The results can be catalogued as follows. First, the reliability in terms of internal consistency of most EPP scales appeared to be adequate. Second, exploratory and confirmatory factor analyses showed that the predicted three-factor structure provided a reasonable fit for EPP data. Third and finally, Extraversion, Neuroticism and Psychoticism correlated in a theoretically meaningful way with the "big 5" supertraits as measured by the FFPI, thereby providing evidence for the validity of the EPP.

In line with previous studies on the reliability of the EPP, the present study found that the internal consistency of the Extraversion scales Dogmatic and Expressive was insufficient (cf. Costa \& McCrae, 1995; Eysenck et al., 1992). This indicates that these lower-order traits are not represented by a homogeneous set of items and that their corresponding EPP scales need further refinement (e.g. reformulation and/or replacement of "bad items") in order to measure their intended personality traits more reliably.

Eysenck et al. (1992) had some difficulties in finding the hypothesized three-factor structure of the EPP. Only when using targeted rotation, the vast majority of the 21 specific EPP traits loaded on the to-be-expected factors Extraversion, Neuroticism and Psychoticism. In contrast, Costa and McCrae (1995) employed factor analysis with varimax rotation and found a rather good fit for the predicted three-factor structure of the EPP. However, neither the Eysenck et al. (1992) nor the Costa and McCrae (1995) study provided a quantitative answer to the question how well the EPP data fit the hypothesized three-factor model. Only the use of confirmatory factor analysis by means of structural equation modeling can resolve this issue. The present study relied on such an approach and found that the three-factor structure provides a moderate fit for the full EPP and a rather satisfactory fit for its short version. Clearly, there is room for improvement. For example, a consistent finding is that Aggressive, which is thought to be a lower-order trait of Extraversion, substantially loads on Psychoticism (see also, Costa \& McCrae, 1995; Eysenck et al., 1992). This suggests that this lower-order trait should best be moved from Extraversion to Psychoticism. Furthermore, as was the case in previous studies (Costa \& McCrae, 1995; Eysenck et al., 1992), Practical does not seem to load positively on 
any of the three supertraits and hence should be dropped from the instrument altogether (see also Costa \& McCrae, 1995).

The current findings are in accordance with earlier work (Goldberg, 1993; Zuckerman et al., 1993) on the relationship between Eysenck's supertraits and the "big 5" factors of personality and should be taken as support for the convergent validity of the EPP. As expected, EPP Extraversion and Neuroticism were significantly linked to their "big 5" counterparts (i.e. FFPI Extraversion and Emotional Stability). Furthermore, some evidence was found for the notion that Psychoticism represents a blending of characteristics that contribute to the separate factors of Agreeableness and Conscientiousness. Note in passing that there has been some debate about this connection between Psychoticism and Agreeableness-Conscientiousness. Whereas Eysenck (1992b) claims Agreeableness and Conscientiousness to be lower-order facets of Psychoticism, Costa and McCrae (1992b) merely view Psychoticism as a conflation of the higher-order traits Agreeableness and Conscientiousness.

Costa and McCrae (1995) argued that the EPP can be better understood in terms of a fivefactor model rather than the intended three-factor model. Although these authors found some support for this claim, they finally concluded: "The recovery of the three-factor model for an instrument designed to measure it is hardly surprising" (p. 315). In other words, the EPP was designed in an attempt to reliably measure 21 specific lower-order traits constituting Eysenck's three supertraits. The current results as well as those of Costa and McCrae (1995) seem to indicate that this attempt was at least to some extent successful, but they should not be interpreted as evidence for the superiority of a three-factor structure of personality. As things stand, five-factor models of personality seem to be equally plausible (see Zuckerman et al., 1993).

An additional finding of the present study concerns the shortened version of the EPP. Results showed that the Short EPP possesses good psychometric properties: reliability was adequate, its factor structure was satisfactory and correlations between Short EPP supertraits and 'big 5' factors were similar to those obtained with the full length EPP. Thus, it seems safe to use the Short EPP in situations where a quick assessment of the basic personality structure is needed.

The EPP was developed to analyze the finer structure of the Extraversion, Neuroticism and Psychoticism superfactors which according to Eysenck (see Eysenck \& Eysenck, 1985) constitute major dimensions of personality. The present data show that the Dutch translation of the EPP has reasonable psychometric properties, although the reliability of some trait scales and the factor structure can certainly be improved. However, as Eysenck (1983) himself already noted, there are two major problems with the measurement of hierarchical personality models: (1) what appears to be a lower-order trait may break down into several subtraits with only relatively small correlations between them and (2) some lower-order traits may tap several higher-order dimensions. Eysenck (see Eysenck et al., 1992, p. 109) was optimistic in dealing with these difficulties: "Problems of this kind are not insoluble and seem simply to represent facets of reality". These are encouraging words for researchers who pursue to further calibrate the EPP to make it an optimal measure of Eysenck's hierarchical model of personality. 


\section{References}

Bentler, P. M. (1989). EQS: structural equations program manual. Los Angeles: BMDP Statistical Software.

Browne, M. W., \& Cudeck, R. (1993). Alternative ways of assessing model fit. In K. A. Bollen, \& J. S. Lonf, Testing structural equation models. Newbury Park, CA: Sage Publications.

Costa, P. T., \& McCrae, R. R. (1992a). Revised NEO Personality Inventory (NEO-PI-R) and NEO Five-Factor Inventory (NEO-FFI), professional manual. Odessa, FL: Psychological Assessment Resources.

Costa, P. T., \& McCrae, R. R. (1992b). Reply to Eysenck. Personality and Individual Differences, 13, 861-865.

Costa, P. T., \& McCrae, R. R. (1995). Primary traits of Eysenck's P-E-N system: three- and five-factor solutions. Journal of Personality and Social Psychology, 69, 308-317.

Eysenck, H. J. (1983). Is there a paradigm in personality research? Journal of Research in Personality, 17, 369-397.

Eysenck, H. J. (1992a). The definition and measurement of psychoticism. Personality and Individual Differences, 13, $757-786$.

Eysenck, H. J. (1992b). Four ways five factors are not basic. Personality and Individual Differences, 13, $667-673$.

Eysenck, H. J., Barrett, P., Wilson, G., \& Jackson, C. (1992). Primary trait measurement of the 21 components of the P-E-N system. European Journal of Psychological Assessment, 8, 109-117.

Eysenck, H. J., \& Eysenck, M. W. (1985). Personality and individual differences. New York: Plenum Press.

Eysenck, H. J., Wilson, G., \& Jackson, C. (1996a). Manual of the Eysenck Personality Profiler. Guilford: Psi-Press.

Eysenck, H. J., Wilson, G., \& Jackson, C. (1996b). Manual of the Eysenck Personality Profiler (Short). Guilford: Psi-Press.

Goldberg, L. R. (1993). The structure of phenotypic personality traits. American Psychologist, 48, 26-34.

Hendriks, A. A. J. (1997). The construction of the Five-Factor Personality Inventory (FFPI). Groningen, The Netherlands: University of Groningen.

Hendriks, A. A. J., Hofstee, W. K. B., De Raad, B., \& Angleitner, A. (1995). The Five-Factor Personality Inventory (FFPI). Groningen, The Netherlands: University of Groningen.

Zuckerman, M., Kuhlman, D. M., Joireman, J., Teta, P., \& Kraft, M. (1993). A comparison of three structural models for personality: the big three, the big five and the alternative five. Journal of Personality and Social Psychology, 65, 757-768. 